\title{
Aplicações de enxertos de bancos de ossos em Odontologia
}

\author{
Graft applications of bone banks in dentistry
}

\begin{abstract}
Delano Oliveira Souza ${ }^{1}$, Erasmo de Almeida $\mathrm{Jr}^{2}$, Isabela Cerqueira Barreto ${ }^{3}$, Thaís Feitosa L. de Oliveira ${ }^{4}$, Roberto Paulo Correia de Araújo ${ }^{5}$

${ }^{1}$ Cirurgião Bucomaxilofacial, Mestrando em Processos Interativos dos Órgãos e Sistemas, Universidade Federal da Bahia; ${ }^{2}$ Mestre em Clínica Odontológica, Doutorando em Processos Interativos dos Órgãos e Sistemas, Universidade Federal da Bahia; ${ }^{3}$ Periodontista, Mestre em Ciências Morfológicas, Doutoranda em Processos Interativos dos Órgãos e Sistemas, Universidade Federal da Bahia; ${ }^{4}$ Cirurgiã - Dentista, Mestranda em Processos Interativos dos Órgãos e Sistemas, Universidade Federal da Bahia; ${ }^{5}$ Professor Titular de Bioquímica do Instituto de Ciências da Saúde da Universidade Federal da Bahia, Universidade Federal da Bahia
\end{abstract}

\begin{abstract}
Resumo
A regeneração de defeitos ósseos representa um grande desafio para a área biomédica, pois muitas lesões produzem sequelas com comprometimentos funcionais ou estéticos que reduzem a qualidade de vida do indivíduo afetado. Sendo assim, enxertos ósseos podem ser utilizados para o tratamento do tecido ósseo perdido. Os enxertos ósseos autógenos são eleitos como os de primeira escolha, pela sua eficiência, biossegurança e facilidade de obtenção, porém apresentam algumas desvantagens e limitações. A utilização de homoenxertos, provenientes de bancos de ossos, representa uma alternativa aos enxertos ósseos autógenos e demonstra ser uma ferramenta bastante útil para a odontologia, com a finalidade de regenerar o tecido ósseo perdido dos maxilares. Este trabalho tem como objetivo realizar uma revisão da literatura sobre as principais aplicações e indicações dos enxertos de bancos de ossos em Odontologia.
\end{abstract}

Palavras-chave: Defeitos Ósseos - Enxertos Ósseos - Odontologia.

\section{Abstract}

The regeneration of bone defects is a major challenge for the biomedical area, because many lesions produce functional's or aesthetic's sequelae which reduce the affected individuals' quality of life. Thus, the use of bone grafts can be employed in an attempt to regenerate the lost bone tissue. Autogenous bone grafts are elected to be the first choice, due to its efficiency, biosecurity and availability to acquire. However, they present some disadvantages and limitations. The use of homogeneous grafts from bone banks proves to be a useful tool for dentistry, in order to regenerate the lost bone tissue jaws. The objective of this paper is to conduct a literature review on the main bone grafts banks' applications in Dentistry.

Keywords: Bone Defects - Bone grafts - Dentistry.

\section{INTRODUÇÃO}

A regeneração de defeitos ósseos representa um grande desafio para a área biomédica, pois muitas destas lesões produzem sequelas, com comprometimentos funcionais ou estéticos e reduzem a qualidade de vida do indivíduo afetado. Assim, a utilização de enxertos ósseos representa uma alternativa viável na tentativa de regeneração do tecido ósseo perdido (BOYNE, 2001; LOGEART-AVRAMOLOU et al., 2005).

Os enxertos de osso autógeno são normalmente eleitos como os de primeira escolha, seja pela sua eficiência, biossegurança ou facilidade de obtenção (TANAKA et al., 2008; WU et al., 2004). Existem, porém, desvantagens e riscos na sua utilização, como a quantidade insuficiente de enxerto da área doadora e consequente necessidade de outro sítio de intervenção cirúrgica, o que gera maior morbidade, desconforto ao paciente e tempo prolongado de recuperação (LEE et al.,

Recebido em 16 de novembro de 2009; revisado em 16 de abril de 2010.

Correspondência / Correspondence: Universidade Federal da Bahia. Av. Reitor Miguel Calmon, s/n, Vale do Canela. 40.110-100 Salvador Bahia Brasil.
2000; LEONETTI; RAMBO; ONG et al., 1998; THRONDSON, 2000). Os enxertos homógenos, provenientes de banco de ossos, representam uma alternativa viável aos enxertos ósseos autógenos na tentativa de regeneração do tecido perdido (ROSS; CAMISA; MICHELIN, 2000). Este trabalho tem como objetivo realizar uma revisão da literatura das principais aplicações e indicações dos enxertos de bancos de ossos na Odontologia.

\section{REVISÃO DE LITERATURA}

O osso é um tecido conjuntivo especializado e mineralizado, que se apresenta em constante remodelação, regulado por fatores locais e hormonais (BEZERRA et al., 2005; SODEK; MCKEE, 2000), e o mecanismo de reparo tecidual ocorre por meio de regeneração, sem a formação de cicatriz fibrosa (DELACURE, 1994). A formação deste tecido necessita do recrutamento de células osteoprogenitoras, seguido pela sua diferenciação, em osteoblastos, formação de matriz osteoide e mineralização (AUBIN; LIU, 1996). A reabsorção do tecido ósseo é viabilizada pela ação de hidrolases e colagenases, além de ácidos fracos, secretados pelos osteoclastos. Estas células tem sua atividade 
coordenada pela ação de citocinas e hormônios, como a calcitonina e paratormônio (HING, 2004).

Apesar da excelente capacidade regenerativa conferida ao tecido ósseo, esta pode ser limitada em situações patológicas onde exista inadequado aporte sanguíneo, distúrbios metabólicos, doenças degenerativas, perdas teciduais extensas devido a traumas, ressecções cirúrgicas decorrentes de neoplasias ou anomalias de desenvolvimento (LOGEARTAVRAMOLOU et al., 2005; SEAL; OTERO; PANITCH, 2001). Nestas situações, em que a morfologia e dimensão do defeito são extensas e críticas ao reparo, o mecanismo regenerativo torna-se limitado e, desta forma, há formação de tecido fibroso (KIM et al., 2006), limitando a qualidade de vida dos indivíduos acometidos por estas lesões.

Diante desta conjuntura, torna-se premente a utilização de terapias de enxertia com o objetivo de regenerar o tecido ósseo perdido. Os enxertos ósseos podem ser classificados em autógeno, quando o doador e receptor são o mesmo individuo; homógeno, quando o osso doado é proveniente de indivíduos da mesma espécie, porém diferentes geneticamente; e heterógeno quando doador e receptor não pertencem à mesma espécie (BAUER; MUSCHLER, 2000; DEVITO et al., 2006; WU et al., 2004). Os enxertos ósseos autógenos apresentam melhores resultados para o reparo do tecido ósseo perdido, pois fornecem as características ideais, como resistência mecânica, osteoblastos viáveis e maior eficiência (MULLIKEN et al., 1980; SCHWARTZ; BOYAN, 2001). Existem, porém, desvantagens e riscos na sua utilização, como a criação de um segundo sítio cirúrgico, como na crista ilíaca, o que está associado à morbidade, além de haver progressiva perda de seu volume, por meio do alto grau de reabsorção (SÀNDOR et al., 2003; YOUGER; CHAPMAN, 1996). A utilização de enxerto homógeno, proveniente de bancos de ossos, passou a despertar bastante interesse aos cirurgiões, por apresentar vantagens, como redução do tempo cirúrgico, menor morbidade, redução de lesões vásculo-nervosas e infecções (DEL VALLE; CARVALHO; GONZALEZ, 2006; JESUSGARCIA et al., 1992). Ademais, quando grandes quantidades de tecido ósseo são requeridas, com consequente dificuldade na obtenção de um enxerto autógeno de dimensões satisfatórias, principalmente em pacientes com idade avançada e comprometimento sistêmico, a indicação mais assertiva encontra-se na utilização de enxertos ósseos provenientes de bancos de ossos (HOLMQUIST et al., 2008; RONDINELLI et al., 1994; STACCHI et al., 2008).

A utilização de órgãos e tecidos homólogos vem aumentando consideravelmente nesta última década, sendo este fato favorecido pela melhoria em técnicas imunossupressoras que facilitam o uso de órgãos, como os rins, coração, pulmões, fígado e tecido ósseo (ROSS; CAMISA; MICHELIN, 2000). Os transplantes ósseos destacam-se pela crescente necessidade reabilitadora de indivíduos portadores de lesões ósseas que podem provocar sequelas, mutilações e morbidades que repercutem no comprometimento funcional ou estético (BOYNE, 2001). Desde 1970, vem ocorrendo crescimento na utilização de ossos homógenos em vários procedimentos ortopédicos, o que favoreceu a criação de banco de ossos, sendo necessário e fundamental estabelecer normas e critérios para regulamentar a doação deste tecido (BIAGINI et al., 1999). Sendo assim, a procura por bancos de ossos tem sido necessária, em virtude do aumento do número de cirurgias para o tratamento de lesões ósseas, bem como para correções de artroses de coluna e traumatismos com perda óssea (MACEDO et al., 1999).

Os doadores potenciais de ossos são indivíduos com constatada morte cerebral, após o consentimento da família, ou pacientes hígidos submetidos a cirurgias eletivas, como as que necessitem de remoção de fragmentos ósseos, como artroplastias de quadril, que também permitam a doação de seus ossos (DEL VALLE; CARVALHO; GONZALEZ, 2006; ROSS; CAMISA; MICHELIN, 2000). Estes fragmentos ósseos captados podem trazer riscos à saúde do receptor, como os de transmissão de doenças, reações imunológicas e infecções (MISCH; DIETSH, 1993) porém, para diminuir estes riscos, hospitais criaram bancos de tecidos músculo-esqueléticos. Estes bancos objetivam a obtenção, processamento, armazenamento e seleção para que os homoenxertos possam ser utilizados com minimização de riscos (DEL VALLE; CARVALHO; GONZALEZ, 2006; RONDINELLI et al., 1994).

A sistemática de retirada, tratamento e armazenamento de tecidos foi descrita pelo pesquisador Imamanaiev na Rússia, na década de 60. A partir de então, grande número de técnicas de conservação e armazenamento, além de pesquisas laboratoriais que visam conservar o potencial osteogênico do enxerto tem sido realizadas. Em 1982, foi criado na cidade de Passo Fundo - Rio Grande do Sul -, o primeiro Serviço de Banco de Ossos institucionalizado do Brasil. Desde então, o material estocado tem sido utilizado de forma regular, com sucesso, em centenas de casos complexos de reconstrução do tecido ósseo (AMATUZZI et al. 2000; ROSS; CAMISA; MICHELIN, 2000).

Normas e rotinas vem sendo discutidas e modificadas ao longo dos anos para melhora da coleta, processamento, armazenamento e doação dos ossos coletados. Os enxertos, tanto de doador vivo quanto de doador ex vivo, são removidos em ambiente cirúrgico estéril, seguindo-se rígidas normas de biossegurança. 0 doador em potencial deve obedecer a critérios para ser admitido para doação, como por exemplo, não possuir história de infecção antes da obtenção do enxerto, ter tido um curso de internação hospitalar afebril, não estar por mais de 72 horas em respirador, não ser acometido por doença crônica ou infecto-contagiosa nem estar sob uso crônico de esteroides (AMATUZZI et al., 2000; FEOFILOFF; JESUS-GARCIA, 1996). 
A remoção dos fragmentos desejados deve ser iniciada pelos membros e, por último, pela remoção de porção do quadril, por ser uma região mais propícia à contaminação. Após a coleta, o enxerto é preparado pela equipe cirúrgica, sendo retirados tecidos moles e cartilagem. Posteriormente, os fragmentos devem ser lavados em solução com antibiótico, retirados pequenos fragmentos e colocados em containers com dupla proteção para realização de cultura (AMATUZZI et al, 2000; ROSS; CAMISA; MICHELIN, 2000). A peça retirada é acondicionada em invólucros simples, em solução antibiótica vancomicina e gentamicina -, selados hermeticamente $e$ encaminhados, sob refrigeração, à temperatura de -4 으, ao banco de tecidos para imediato processamento (AMATUZZI et al., 2000; ROSS; CAMISA; MICHELIN, 2000).

Os enxertos são armazenados em temperatura inferior a -70 ㅇ, em containers, separados temporariamente, até os resultados dos exames laboratoriais. Caso haja deteç̧ão de alguma patologia ou o doador vivo desenvolva infecção, o enxerto deverá ser descartado ou, se houver liberação para utilização do enxerto, ele pode ser estocado por até cinco anos. Em todos os enxertos, são realizadas tomadas radiográficas, com o objetivo de detectar lesões preexistentes ou malformações ósseas que possam prejudicar o receptor (AMATUZZI et al., 2000; FEOFILOFF; JESUS-GARCIA, 1996; ROSS; CAMISA; MICHELIN, 2000). Os homoenxertos devem ser submetidos a processamento com o objetivo de esterilização e redução da antigenicidade, mas com manutenção das suas características biológicas. Para o processamento, podem-se utilizar ácidos, como o ácido clorídrico, associado a uma solução composta por cálcio a 5\%, bombeamento em água por 12 horas, liofilização, e armazenamento a $-80{ }^{\circ} \mathrm{C}$. Tal etapa garante a esterilização e a preservação das propriedades osteocondutivas, osteoestimuladoras e osteoindutoras. Entretanto, a cuidadosa seleção do doador é fundamental na prevenção da transmissão de doenças infecto-contagiosas (VASTEL et al., 2004).

A preocupação com a minimização de danos na remoção de ossos em doadores vivos e de reconstrução em doadores-cadáver é uma constante. No doador ex vivo, a reconstrução é obtida com artifícios protéticos, como ossos de plástico, calha de Küntscher e cimento acrílico (AMATUZZI et al., 2000; JESUS-GARCIA et al., 1992).

Especialidades odontológicas, como periodontia, ortodontia, implantodontia e cirurgia e traumatologia bucomaxilofacial, utilizam os enxertos ósseos como um poderoso recurso terapêutico para tratamento de lesões ósseas dos maxilares (DEL VALLE; CARVALHO; GONZALEZ, 2006). A instalação de implantes dentários representa uma técnica segura e previsível para reabilitação mastigatória de pacientes que apresentam perda dentária, porém, em alguns pacientes, a severa reabsorção óssea, que culmina com a atrofia do rebordo alveolar, pode dificultar ou inviabilizar a reabilitação por implantes dentários, tornando imperativa a reconstrução do rebordo alveolar, que pode ser facilitada com o emprego do enxerto homógeno (Figura 1) (HOLMQUIST et al., 2008; REIS et al., 2008). Os enxertos ósseos tem sido utilizados no intuito de incrementar o processo de regeneração óssea, sendo que os homógenos, provenientes de banco de ossos, surgem como uma alternativa nas cirurgias reconstrutivas por possuirem vantagens, como seu potencial osteoindutor, possibilidade de armazenamento, disponibilidade, resistência mecânica e por eliminarem a necessidade de um sítio doador do próprio paciente (FONTANARI; MANNE; TREVISAN JÚNIOR, 2008).

Cirurgia paraendodôntica, regeneração periodontal, cirurgia ortognática, levantamento de seio maxilar e reconstrução de rebordo alveolar atrófico representam algumas das indicações para o uso de enxerto ósseo homólogo na odontologia. Com relação ao uso de enxerto ósseo em levantamento de seio maxilar, Costa e Trevisan Júnior (2007) relatam um caso clínico onde se utilizou enxerto ósseo homólogo, do banco de ossos do Hospital de Clínica de Curitiba, mostrando a utilização deste tipo de enxerto ósseo como uma alternativa em casos de atrofia em região posterior de maxila, oferecendo, desta maneira, um menor grau de morbidade aos pacientes no trans e pós-cirúrgico. Após a cirurgia, foram realizadas biópsias que comprovaram osteogênese na área receptora do enxerto homógeno (COSTA; TREVISAN JUNIOR, 2007).

Figura 1. Sequência de fotos de paciente que apresentava rebordo alveolar atrófico (Figuras 1a e 1b), submetido a cirurgia com enxerto ósseo homógeno (Figura 1c), proveniente de banco de ossos, para aumento de rebordo alveolar para futura instalação de implantes na região ântero-superior da maxila (Figuras $1 \mathrm{~d}, 1 \mathrm{e}, 1 \mathrm{f}$ ). Fotos cedidas pelo cirurgião-dentista Delano Oliveira Souza.

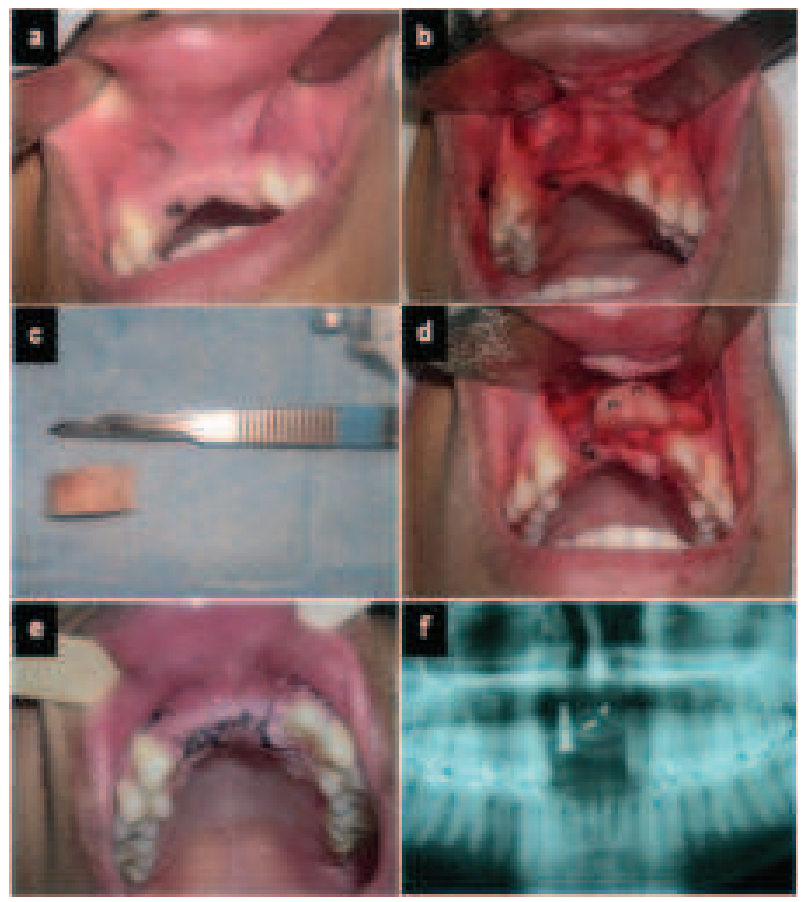


Segundo Figueiredo et al. (2008), o uso de enxerto ósseo homógeno, proveniente de banco de ossos, previamente à instalação de implantes, representa uma alternativa viável para o aumento do volume de rebordo ósseo. Os enxertos ósseos homógenos, após estudo histopatológico, demonstraram ser biocompatíveis, com sucesso reparativo e ausência de reação imunológica (HOLMQUIST et al., 2008; RONDINELLI et al., 1994; STACCHI et al., 2008).

\section{CONSIDERAÇÕES FINAIS}

A utilização de homoenxertos provenientes de bancos de ossos demonstra ser uma ferramenta bastante útil para a odontologia, com a finalidade de regenerar o tecido ósseo perdido dos maxilares. Faz-se necessário que mais bancos de coleta e preparo do tecido ósseo sejam instalados nos hospitais para que esta opção torne-se viável e acessível a um número maior de serviços que atuam com reconstruções ósseas.

\section{REFERÊNCIAS}

1. AMATUZZI, M. M. et al. Banco de tecidos: estruturação e normatização. Rev. Bras. Ortop., v. 35, n. 5, p. 165-172, 2000.

2. AUBIN, J. E.; LIU, F. The osteoblast lineage. In: Bilizekian, J., Raisz, L., and Rodan, G., editors. Principles of Bone Biology. San Diego, CA: Academic Press: 1996, p. 39-50.

3. BAUER, T. W.; MUSCHLER G. F. Bone graft materials: an overview of the basic science. Clin. Orthop. Relat. Res., v. 371, p. 10-27, 2000

4. BEZERRA, M. C. et al. RANK, RANKL and osteoprotegerin in arthritic bone loss. Braz. J. Med. Biol. Res., v. 38, n. 2, p. 161170, 2005.

5. BIAGINI, S. et al. Padronização da rotina operacional em banco de ossos realizada por um serviço hemoterápico: proposta de elaboração de normas. Rev. Bras. Ortop., v. 34, n.6, p. 381-384, 1999.

6. BOYNE, P. J. Application of bone morphogenetic proteins in the treatment of clinical oral and maxillofacial osseous defects. J. Bone. Joint. Surg. Am., California, v. 83-A, Supplement 1, part 2, p.146-151, 2001.

7. COSTA, R. R.; TREVISAN JÚNIOR, W. Levantamento de seio maxilar bilateral com a utilização de osso homógeno de banco de ossos: uma alternativa viável. ImplantNews, v. 4, n. 5, p. 513-520, 2007.

8. DELACURE, M. Physiology of bone healing and bone grafts. Otolaryngol. Clin. North Am., v. 27, n. 5, p. 859-874, 1994.

9. DEL VALLE, R. A.; CARVALHO, M.L.; GONZALEZ, M.R. Estudo do comportamento de enxerto ósseo com material doador obtido dos bancos de tecidos músculo - esqueléticos. Rev. Odontol. Univ. São Paulo, v. 18, n. 2, p. 189-194, 2006.

10. DEVITO, F. S. et al. O uso de enxerto homólogo na revisão de artroplastia do quadril com cimentação do componente acetabular. Acta Ortop. Bras., v. 14, n. 5, p. 280-282, 2006

11. FEOFILOFF, E. T.; JESUS-GARCIA, R. Técnicas de obtenção, processamento, armazenamento e utilização de homoenxertos ósseos. Rev. Bras. Ortop. v. 31, n. 11, 1996.

12. FIGUEIREDO, M. N. et al. Enxerto ósseo homólogo como alternativa na enxertia do rebordo maxilar atrófico. ImplantNews, v. 5, n.3, p. 269-274, 2008.

13. FONTANARI, L. A.; MANNE, J. M.; TREVISAN JÚNIOR, W. Utilização de enxerto ósseo homógeno para reconstrução em áreas atróficas pré-implante: banco de ossos. ImplantNews, v. 5, n. 6, p. 593-597, 2008.

14. HING, K. A. Bone repair in the twenty-first century: biology, chemistry or engineering? Philos. Trans. R. Soc. Lond. B. Biol Sci., v. 362 , n. 1825 , p. 2821-2850, 2004.
15. HOLMQUIST, P. et al. A new technique for reconstruction of the atrophied narrow alveolar crest in the maxilla using morselized impacted bone allograft and later placement of dental implants. Clin. Implant. Dent. Relat. Res., v. 10, n. 2, p. 86-92, 2008.

16. JESUS-GARCIA, R. et al. Enxerto homólogo de banco no tratamento de tumores ósseos. Experiência inicial da Escola Paulista de Medicina. Rev. Bras. Ortop., v. 27, n. 11/12, p. 844848, 1992.

17. KIM, S. S. et al. Poly (lactide-coglycolide)/hydroxyapatite composite scaffolds for bone tissue engineering. Biomaterials., v. 27, n. 8, p. 1399-1409, 2006.

18. LEE, Y. M. et al. Tissue engineered bone formation using chitosan/tricalcium phosphate sponges. J. Periodontol., v.71, n.3, p. 410-417, 2000.

19. LEONETTI, J. A.; RAMBO, H. M; THRONDSON, R. R. Osteotome sinus elevation and implant placement with narrow size bioactive glass. Implant. Dent., v. 9, n. 2, p. 177-182, 2000.

20. LOGEART-AVRAMOGLOU, D. et al. Engineering bone: challenges and obstacles. J. Cell. Mol. Med., v. 9, n. 1, p. 72-84, 2005.

21. MACEDO, C. A. S. et al. Comparação da resistencia à compressão do osso bovino congelado e liofilizado. Rev. Bras. Ortop., v. 34, n. 9/10, p. 529-534, 1999.

22. MISCH, C. E.; DIETSH, F. Bone-grafting materials in implant dentistry. Implant. Dent., v.2, n.3, p.158-167, 1993.

23. MULLIKEN, J. et al. Use of demineralized allogeneic bone implants for the correction of maxillocraniofacial deformities. Ann. Surg., v.194, p.366-372, 1980.

24. ONG, M. M. et al. Evaluation of a bioactive glass alloplast in treating periodontal intrabony defects. J. Periodontol., v.69, p.1346-1354, 1998

25. REIS, L. F. et al. Reabilitação com implantes após enxerto ósseo. Revista Dens, v.16, n.2, p. 41-48, 2008.

26. RONDINELLI, P. C. et al. Rotina do banco de ossos do hospital de traumato-ortopedia (HTO-RJ). Rev. Bras. Ortop., v. 29, n. 6, p. 385-389, 1994.

27. ROOS, M. V.; CAMISA JR., A.; MICHELIN, A. F. Procedimentos de um banco de ossos e a aplicabilidade dos enxertos por ele proporcionados. Acta Ortop. Bras., Passo Fundo, v.8, n.3, p. 122127, Jul/Set, 2000.

28. SÀNDOR, G.K.B. et al. Preservation of ridge dimensions following grafting with coral granules of 48 post traumatic and post-extraction dento-alveolar defects. Dent. Traumatol., v.19, p.221-227, 2003.

29. SCHWARTZ, Z.; BOYAN, B.D. Tissue banking of bone allografts used in periodontal regeneration. J. Periodontol., v. 72, n.6, p. 834-837, 2001.

30. SEAL, B. L.; OTERO, T. C.; PANITCH, A. Polymeric biomaterials for tissue and organ regeneration. Mater. Sci. Eng., v. 34, p. 14730, 2001.

31. SODEK, J.; MCKEE, M. D. Molecular and cellular biology of alveolar bone. Periodontol. 2000., v. 24, p. 99-126, 2000.

32. STACCHI, C. et al. Clinical, Histologic, and histomorphometric analyses of regenerated bone in maxillary sinus augmentation using fresh frozen human bone allografts. J. Periodontol., v. 79, n. 9, p. 1789-1795, 2008.

33. TANAKA, R. et al., Incorporação dos enxertos ósseos em bloco: processo biológico e considerações relevantes. ConScientiae Saúde, v. 7, n. 3, p. 323-327, 2008.

34. WU, T. J. et al. Studies on microspheres comprised of reconstituted collagen and hydroxyapatite. Biomaterials., v. 25, n. 4, p. 651-658, 2004.

35. YOUGER, E.M.; CHAPMAN, M.W. Morbidity at bone graft donor sites. J. Orthop. Trauma., v. 3, p. 192-195, 1996.

36. VASTEL, L. et al. Effect of different sterilization processing methods on the mechanical properties of human cancellous bone allografts. Biomaterials., v. 25, p. 21052110, 2004. 